\title{
OPTIMALISASI PEMILIHAN PORTOFOLIO SAHAM MENGGUNAKAN FUZZY LINEAR PROGRAMMING BERBASIS KOMPUTER
}

\section{Optimization of Stock Portfolio Selection Using Computer Based Fuzzy Linear Programming}

\author{
Ngarap Imanuel Manik, manik@binus.ac.id ${ }^{1}$, Aga Rasyidi Sukandar \\ aga.sukandar@gmail.com ${ }^{2)}$ \\ ${ }^{12)}$ Mathematics Departement, School of Computer Science, Bina Nusantara University
}

\begin{abstract}
Investing in the stock area is one of the popular category of investment nowadays. To get the maximum profit in stock trading, user usually creates a portfolio. In this paper describe the Fuzzy Linear Programming approach to optimize the stock proportion in the Markowitz's portfolio selection model. Computer based program with PHP programming language are made to facilitate and improve the accuracy in the calculation of the optimal allocation of the stock portfolio selection. The computer program are able to passively analyze 45 best stocks contained in the Indonesia Stock Exchange.
\end{abstract}

Keywords: Portfolio, Stock, Fuzzy Linear Programming, Optimization

\begin{abstract}
ABSTRAK
Berinvestasi pada bidang saham semakin diminati akhir-akhir ini. Untuk mendapatkan keuntungan yang maksimal dalam bertransaksi, ada kalanya perlu dibuat sebuah portofolio. Dalam makalah ini dibahas pendekatan Fuzzy Linear Programming untuk mengoptimasi pemilihan portofolio saham pada model Markowitz. Program komputer berbasis bahasa pemrograman PHP juga telah dibuat untuk mempermudah dan meningkatkan akurasi dalam penghitungan alokasi optimal pada pemilihan portofolio tersebut. Hasil dari program komputer yang dibuat dapat menganalisa secara pasif 45 saham terbaik yang terdapat di Bursa Efek Indonesia.
\end{abstract}

Kata Kunci: Portofolio, Fuzzy Linear Programming, Optimalisasi

\section{PENDAHULUAN}

Investasi secara garis besar ialah penundaan konsumsi sekarang untuk digunakan di dalam produksi yang efisien selama periode waktu tertentu. Investasi pada dunia ekonomi dan saham yang kita kenal secara lebih khusus artinya ialah kegiatan menanamkan modal baik secara langsung atau tidak, untuk mendapatkan keuntungan sebesar-besarnya dengan resiko sekecil mungkin. Untuk meminimalisir resiko yang timbul oleh aktivitas investasi tersebut, maka dibuat portofolio investasi.[12] Pada dunia investasi saham, portfolio investasi yang disebut portofolio saham merupakan sarana untuk meminimalisir kerugian dan memaksimalkan keuntungan. Langkah yang ditempuh ialah dengan memilih untuk membeli beberapa saham yang berbeda dengan memperhitungkan bobot yang maksimal untuk menghasilkan kombinasi yang optimal.

Kegiatan menentukan bobot alokasi saham pada dasarnya telah dilakukan jauhjauh hari sebelum investasi saham telah berkembang seperti sekarang. Adalah seorang Harry Markowitz yang pada tahun 
1952 telah melakukan perhitungan secara kuantitatif yang menghasilkan sebuah model untuk menghitung bobot alokasi pembelian saham, yang lalu sampai saat ini dikenal luas sebagai model Markowitz.

Proses pembentukan alokasi bobot pada portofolio saham seringkali menemukan kendala akan banyaknya jumlah saham yang diperbandingkan untuk dibeli. Jumlah saham yang diperdagangakan di Bursa Efek Indonesia sampai Desember 2019 mencapai 670 saham dan akan terus bertambah dari tahun ke tahun seiring ramainya IPO (Initial Public Offer) dan peningkatan kemakmuran ekonomi [10] Walaupun pada akhirnya penelitian hanya terbatas pada 45 saham unggulan di bursa, namun investor tetap harus mengetahui bobot masing masing saham untuk mengetahui banyak kemungkinan solusi dari pembentukan protfolio saham kelak. Perhitungan bobot alokasi saham secara manual dengan banyaknya kombinasi saham dan data-data di dalamnya menghasilkan suatu kesulitan tersendiri dan membutuhkan tingkat ketelitian yang sangat tinggi. Oleh karena itu, penggunaan perangkat lunak komputer kini mutlak diperlukan untuk mempermudah proses alokasi dan mempercepat pengambilan keputusan.

Perangkat lunak yang saat ini banyak digunakan untuk menentukan alokasi bobot saham yang dimasukkan kedalam portfolio masih menggunakan rumusan dan formula lama dalam praktiknya. Seiring dengan berkembangnya ilmu matematika dan beberapa penelitian-penelitian seputar optimasi saham menurut kaidah matematika, maka dari itu inovasi di bidang perangkat lunak optimasi pemilihan portfolio saham mutlak harus dilakukan untuk menambah akurasi dan reliabilitasnya.

Pada masalah pembentukan sebuah portofolio saham, data yang digunakan untuk memperbandingkan ialah data yang sifatnya fuzzy (kabur) dikarenakan dinamika perubahan pada data saham yang relatif tinggi, oleh karena itu dibutuhkan sebuah metode yang tepat untuk penentuan bobot alokasi diluar metode biasa yang sering digunakan pada saat ini seperti Quadratic Programming maupun algoritma genetika. Oleh karena itu dipilihlah metode Fuzzy Linear Programming yang merupakan metode optimasi pengembangan dari Linear Programming namun dengan kendala atau constraint yang fuzzy.[11]

Ada beberapa hasil penelitian yang relevan dengan penelitian ini seperti Eko Hari Parmadi membahas tentang penerapan program linear berkendala fuzzy untuk optimalisasi produksi gerabah.[2]. HongWei Liu. Linear Programming for Portfolio Selection Based on Fuzzy Decision Making Theory. menulis tentang Pemilihan portofolio saham menggunakan linear programming berdasarkan teori pembuatan keputusan fuzzy. Yang merupakan dasar dalam pembuatan model penyelesaian kasus pemilihan portofolio saham menggunakan Fuzzy Linear Programming serta membuat program komputernya.[5]

Wawan T. N., Silvia R juga telah menulis penggunaan algoritma genetika untuk pemilihian portofolio saham serta penjelasan mengenai prinsip model Markowitz untuk pemilihan portofolio saham[7]. Masahiro Inuiguchi, Jaroslav Ramik, Menjelaskan masalah "Possibilistic linear programming: a brief review of fuzzy mathematical programming and a comparison with stochastic programming in portfolio selection problem. Fuzzy Sets and Systems 1". Makalah ini berisi tentang perbandingan metode yang digunakan pada masalah pemilihan portofolio saham yang optimal, antara Fuzzy Mathematical Programming dan Stochastic Programming. [ 8]

Guohua Chen, Shou Chen, Yong Fang, Shouyang Wang. Meneliti penggunaan himpunan fuzzy untuk pemilihan portofolio saham.[11] Dalam makalah ini dibahas bagaimana pemilihan portofolio saham yang optimal dengan menggunakan metode Fuzzy Linear Programming yang perhitungannya dibantu oleh program komputer. Adapun tujuannya adalah untuk mencari strategi yang tepat dalam mendapatkan kombinasi saham yang optimal berdasarkan batasan-batasan yang ada. 


\section{METODE PENELITIAN}

Model Pemilihan Portofolio Pada Kasus Fuzzy dijelaskan sebagai berikut: Di dalam proses investasi, pengetahuan dan pengalaman para ahli sangat penting dalam pengambilan keputusan seorang investor. Didasarkan pada kompleksitas dan tidak terprediksinya pasar keuangan, akan sangat menyulitkan untuk memberikan nilai yang tepat untuk prediksi atas risiko dan return, namun hal itu dapat diatasi dengan membentuknya menjadi fungsi tujuan fuzzy. Menurut Guohua Chen [3] return dapat dibentuk menjadi nilai fuzzy dengan membuatnya dalam bentuk bilangan fuzzy trapesium $F^{n}=\left(r_{2}, r_{2}, r_{3}, r_{4}\right)$ dimana $r_{1}<r_{2} \leq r_{3}<r_{4}$. Fungsi keanggotaan dari bilangan fuzzy $\tilde{\mathrm{r}}$ dapat dinotasikan pada persamaan (1).

$\mu(x)\left\{\begin{array}{c}x-r_{1}, \quad r_{1} \leq x \leq r_{2} \\ r_{2}-r_{1}, \\ 1, r_{2} \leq x \leq r_{3} \\ x-r_{4}, \quad r_{3} \leq x \leq r_{3} \\ r_{3}-r_{4}, \\ 0, \text { lainnya }\end{array}\right.$.

Bilangan fuzzy trapezium akan menjadi bilangan fuzzy segitiga apabila terjadi $r_{2}=r_{3}$. Selain itu, yang menjadi pertimbangan dalam menentukan proporsi saham yang optimal pada portofolio ialah nilai VaR atau Value at Risk. Dimana nilai ini ialah nilai diberikan toleransi resiko yang dapat ditanggung oleh investor. Nilai $\mathrm{VaR}$ dirumuskan secara fuzzy dan disimbolkan melalui bilangan fuzzy trapezium $\tilde{b}=\left(b_{1}, b_{2}, b_{3}, b_{4}\right)$.

Untuk menentukan proporsi saham optimal yang sesuai dengan tingkat return yang maksimal pada suatu tingkat. Guohoa Chen juga telah merumuskan pemrograman linear fuzzy untuk pemilihan portofolio saham optimal yang dapat dikemukakan sesuai dengan model persamaan 2 [3][6]

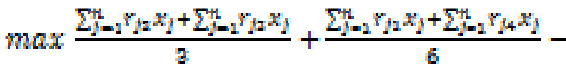
$\sum_{j=1} c_{j} x_{j}$

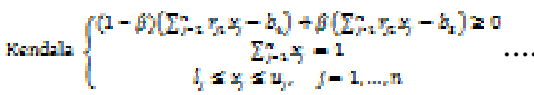

Keterangan:

$$
\begin{aligned}
& \eta_{j}=\text { Retwm ekspehtasi saham ke }-1 \\
& x_{j}=\text { Proporsi saham ke }-\mathrm{j} \\
& c_{j}=\text { Biaya transaks saham ke }-1 \\
& b=\text { Nilai Value at Risk bertipe fuzzy } \\
& h_{j}=\text { Batas minimum proporsi saham ke }-\mathrm{j} \\
& v_{j}=\text { Batas maksimum proporsi sahamke }-\mathrm{j} \\
& \rho=\text { Nilai beta saham }
\end{aligned}
$$

Dari rumusan Fuzzy Linear Programming tersebut kemudian dirancanglah program komputer untuk membantu proses perhitungannya.

Use-Case diagram sesi admin dapat dilihat pada Gambar 1. Admin dapat melakukan dua kegiatan utama, yaitu login untuk masuk kedalam sistem situs web dan melakukan input berita-berita kedalam situs web.

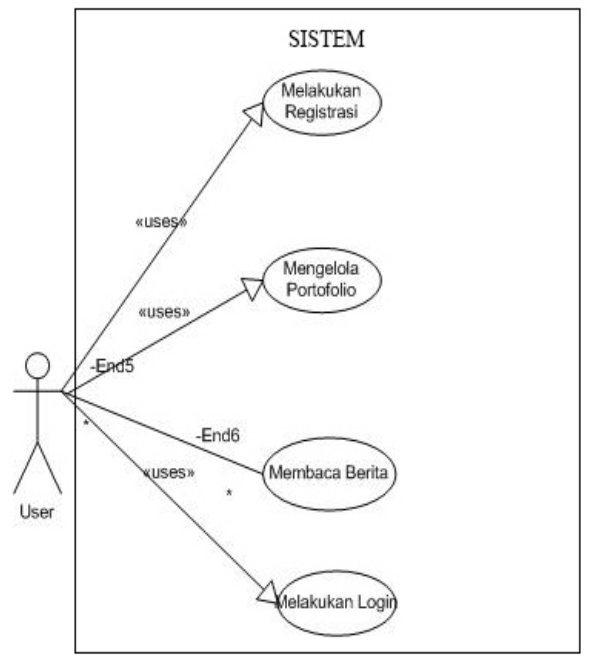

\section{Gambar 1. Use-Case Diagram User}

Hierarki Menu dapat dilihat pada Gambar 2. Dijelaskan bagaimana susunan menu-menu pada program aplikasi optimasi pemilihan portofolio saham ini. Program aplikasi terdiri dari 6 menu utama yaitu menu Beranda, Kelola Portofolio, Berita \& Artikel, Tentang, Daftar dan Masuk. 


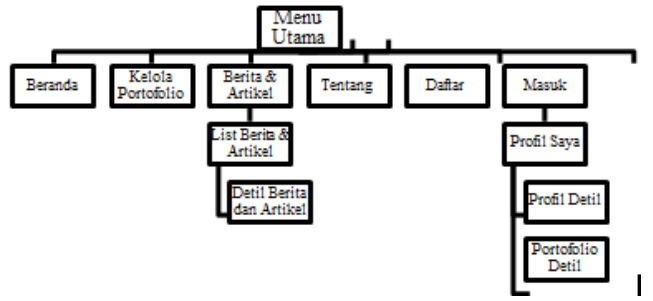

Gambar 2. Hierarki Menu

Berbagai bentuk activity diagram yang telah dibuat, salah satunya adalah activity diagram sesi user. Pada activity diagram sesi user yang diperagakan pada Gambar 3. Dijelaskan bagaimana user melakukan proses mengelola portofolio saham dalam program. Pertama kali, user melakukannya dengan menekan hyperlink menu Kelola Portofolio, apabila hal tersebut telah dilakukan, secara otomatis sistem memunculkan halaman Kelola Portofolio yang berisi daftar saham LQ45 yang berupa radio button beserta form isian nama portofolio saham dan besar proporsi saham diinginkan. Setelah form keluar, user diharuskan untuk mengisi form tersebut secara benar dan lengkap lalu menekan tombol "lanjut". Setelah tombol ditekan, sistem secara otomatis akan menjalankan algoritma Fuzzy Linear Programming untuk kemudian mencari proporsi optimal saham dan langsung ditampilkan pada halaman selanjutnya.

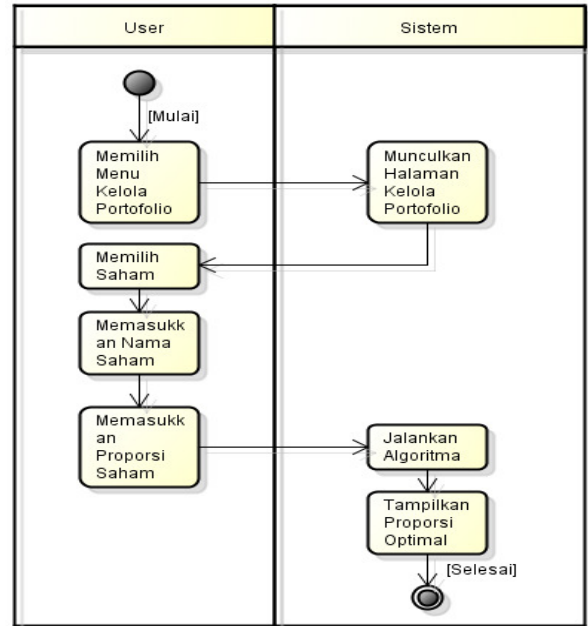

\section{Gambar 3. Activity Diagram User Mengelola Portofolio}

Rancangan database untuk masalah ini dapat dilihat pada gambar 4. Sedangkan tahap akhir dari semua kegiatan dalam perancangan ini adalah membuat rancangan layar program.[4]

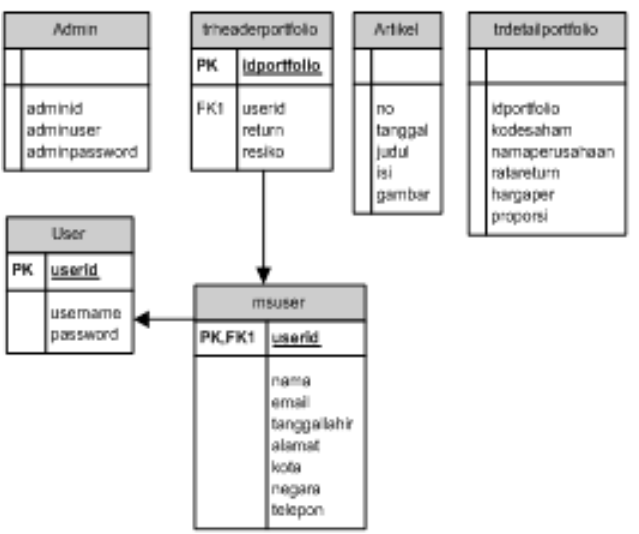

Gambar 4. Rancangan Database

\section{HASIL DAN PEMBAHASAN}

Dalam melakukan proses coding program, dilakukan integrasi antara bahasa pemrograman PHP sebagai back-end, bahasa HTML sebagai front-end dan database menggunakan MySQL.Kemudian untuk penerapannya diambil contoh kasus sebagai berikut:

Seorang investor ingin menginvestasikan uangnya dalam bentuk investasi saham. Pada awalnya sang investor membentuk portofolio yang berisi 5 saham dari indeks LQ45, saham saham tersebut adalah : PT. AT, Tbk. ; PT. AI, Tbk; PT. XLA, Tbk; PT. MNC, Tbk. Dan PT. UI, Tbk.

Melalui penghitungan data harga saham perbulan dan dividen tahunan dari tahun 2018 - 2020, didapatkan hasil berupa return ekspektasi dan biaya transaksi dengan detil yang tergambar pada Tabel 1 .

Tabel 1. Tabel Data Return dan Resiko Saham

\begin{tabular}{|l|c|c|}
\hline \multicolumn{1}{|c|}{$\begin{array}{c}\text { Nama } \\
\text { Perusahaan }\end{array}$} & \multicolumn{1}{c|}{$\begin{array}{c}\text { Return } \\
\text { Ekspektasi }\end{array}$} & $\begin{array}{c}\text { Biaya } \\
\text { Transaksi }\end{array}$ \\
\hline PT. AT, Tbk. & 0.039419922 & 0 \\
\hline PT. Al, Tbk. & 0.06244127 & 0.001 \\
\hline PT. XLA, Tbk. & 0.022406195 & 0.001 \\
\hline PT. MNC, Tbk. & 0.056086912 & 0.002 \\
\hline
\end{tabular}




\begin{tabular}{l|l|l} 
PT. Uln Tbk. & 0.025297958 & 0.003 \\
\hline
\end{tabular}

Setelah didapat data return ekspektasi dan resiko dari masing-masing saham yang akan dimasukkan ke dalam portofolio. Data berikutnya yang diperlukan adalah tingkat toleransi $\mathrm{VaR}, \quad \beta$ dan proporsi maksimal yang diperbolehkan dari tiap saham. Data dari VaR, $\beta$ dan proporsi maksimal $\left(\boldsymbol{u}_{j}\right)$ adalah sebagai berikut :

Fuzzy VaR Level $(\tilde{\hat{b}})=$ $(0.04 ; 0.046 ; 0.048 ; 0.05) ; \beta=0.05$ dan Proporsi maksimal tiap jenis saham $\left(u_{j}\right)$ : 0.39

Pada bagian ini akan dijelaskan bagaimana program aplikasi dijalankan dan berinteraksi dengan user. Data-data yang diperlukan untuk menjalankan program aplikasi optimasi pemilihan portofolio saham menggunakan fuzzy linear programming ini berasal dari database detil saham dalam 3 tahun terakhir. Adapun data-data yang diperlukan dari database tersebut antara lain : data harga saham, data return saham LQ45, data berita-berita terbaru seputar saham. Kemudian hasil running program dimaksud dapat dilihat pada gambar $5 \mathrm{~s} / \mathrm{d}$ gambar 10.

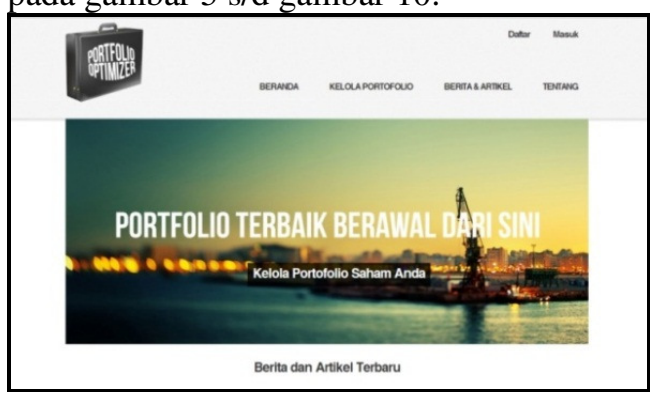

Gambar 5. Halaman Beranda

Gambar 5 adalah Halaman "Beranda" yaitu halaman pertama yang akan ditampilkan pada saat program dijalankan. Pada halaman ini terdapat menu utama yang terdapat di bagian atas program. Menu tersebut antara lain : Beranda, Kelola Portofolio, Berita \& Artikel, Tentang, Daftar dan Masuk. Pada halaman ini juga terdapat kumpulan berita $\&$ artikel terbaru untuk dilihat oleh user. Untuk dapat menggunakan fitur kelola portofolio, user diwajibkan untuk mendaftar dan masuk terlebih dahulu. Link daftar akan mengarahkan user kepada layar berikutnya yaitu layar daftar gambar 6 .

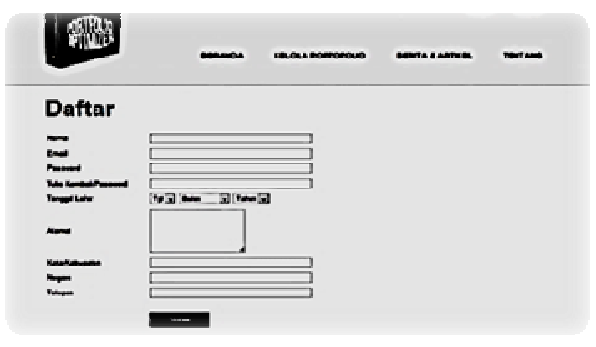

Gambar 6. Halaman Daftar

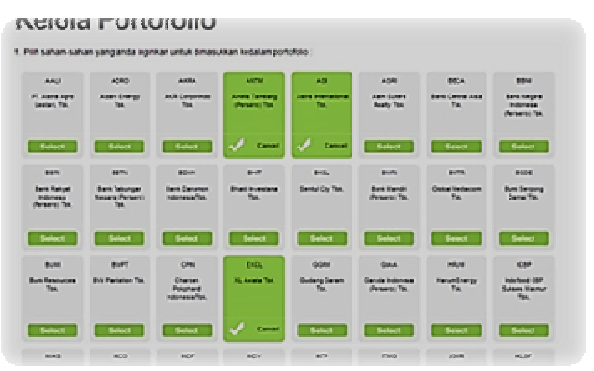

Gambar 7. Halaman Kelola Portofolio

Gambar 7. Adalah halaman kelola portofolio yang akan muncul apabila user menekan link "Kelola Portofolio" pada menu utama. Pada halaman ini, user dapat memilih beberapa kombinasi saham dengan cara menekan tombol pilih yang terdapat di setiap kotak saham. Pada halaman ini, user juga memasukkan nama portofolio yang telah dibentuk. Setelah memasukkan nama portofolio, user diharuskan menekan tombol lanjut untuk memproses kombinasi portofolio saham yang optimal dan akan ditampilkan di layar berikutnya, seperti pada gambar 8 .

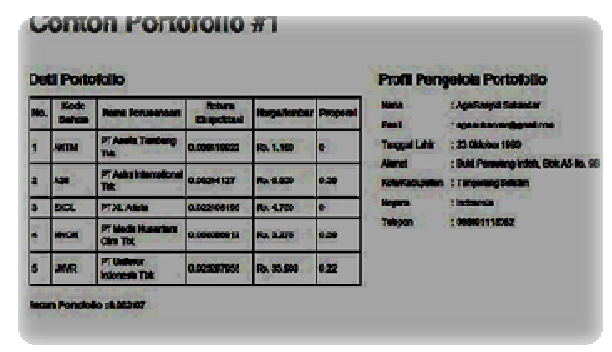

\section{Gambar 8. Halaman Detil Portofolio}

Pada halaman detil portofolio yang diperagakan oleh Gambar 9, user akan 
dapat melihat kombinasi dan proporsi dari masing-masing saham yang telah dibentuk. User juga dapat melihat profil dirinya yang telah membentuk portofolio tersebut.

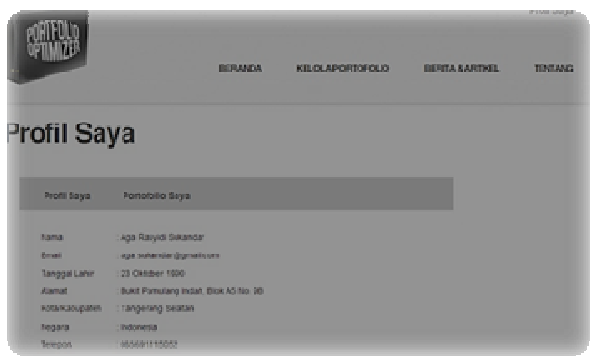

Gambar 9. Halaman Profil Saya

Halaman berita \& artikel pada Gambar 10 akan muncul apabila user menekan link "Berita \& Artikel" pada menu utama. Halaman berita \& artikel akan menampilkan berita-berita terbaru yang telah diinput oleh admin. Apabila judul berita ditekan, maka akan mengakomodasi perpindahan layar ke layar berikutnya yaitu detil berita.

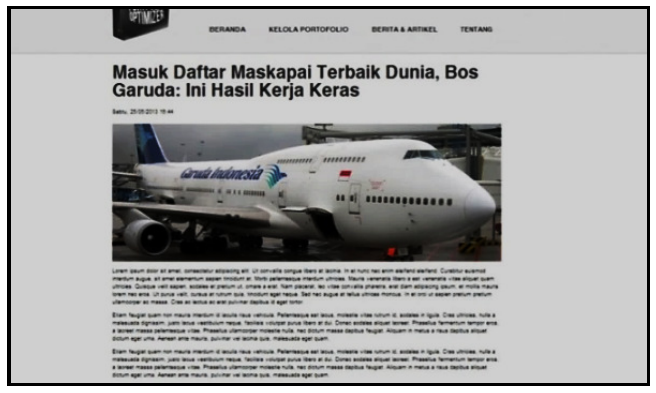

Gambar 10 Halaman Detil Berita

Halaman detil berita yang diperagakan oleh Gambar 10 dapat dicapai dengan cara menekan link judul yang terdapat pada halaman berita \& artikel. Halaman detil berita menampilkan penjabaran berita yang lengkap beserta tanggal dimuatnya berita dan gambar terkait berita.

Setelah melakukan penghitungan numerik secara manual dan melalui implementasi lewat program aplikasi, didapatkan hasil dari kedua metode tersebut seperti yang diperagakan oleh tabel 2 .

Tabel 2. Tabel Perbandingan Hasil

\begin{tabular}{|l|c|c|c|}
\hline \multirow{2}{*}{$\begin{array}{c}\text { Nama } \\
\text { Perusahaan }\end{array}$} & \multirow{2}{*}{$\begin{array}{c}\text { Return } \\
\text { Ekspektasi }\end{array}$} & \multicolumn{2}{|c|}{ Proporsi Optima } \\
\cline { 3 - 4 } & & Manual & Program \\
\hline PT. AT, Tbk. & 0.039419922 & 0 & 0 \\
\hline PT. AI, Tbk. & 0.06244127 & 0.39 & 0.39 \\
\hline PT. XLA, Tbk. & 0.022406195 & 0 & 0 \\
\hline PT. MNC, Tbk. & 0.056086912 & 0.39 & 0.39 \\
\hline PT. UI, Tbk. & 0.025297958 & 0.22 & 0.22 \\
\hline
\end{tabular}

Hasil akhir yang sama dari kedua percobaan baik secara manual ataupun menggunakan program menandakan program aplikasi dapat diandalkan untuk menghitung optimasi pemilihan portofolio saham.

\section{SIMPULAN}

\section{Simpulan}

Berdasarkan hasil analisa yang dilakukan dari pembuatan program aplikasi optimasi pemilihan portofolio saham menggunakan fuzzy linear programming ini, dapat disimpulkan: Pemilihan saham dalam portofolio saham dapat dioptimalkan melalui metode Fuzzy Linear Programming. Program aplikasi untuk optimasi pemilihan portofolio saham dapat dibuat secara baik pada teknis dan konsepnya melalui perancangan program dan program dapat digunakan untuk membentuk portofolio saham dari sahamsaham yang terdaftar di indeks LQ45 Bursa Efek Indonesia melalui sebuah strategi yang dirumuskan seperti terdapat pada Bab Implementasi dan Hasil Evaluasi.

\section{DAFTAR PUSTAKA}

[1] Billbao,T.A., Perz,G.B., Arenas,P. M. and Rodriguez,U.M.V. Fuzzy compromise Programming for Portfolio Selection, Applied Mathematics and Computation, 2016, 173:251-264.

[2] Eko Hari Parmadi. Penerapan Program Linear Berkendala Fuzzy untuk Optimalisasi Produksi Gerabah. Seminar Nasional Informatika UPN Veteran Yogyakarta (2010). 
[3] Guohua Chen, Shou Chen, Yong Fang, Shouyang Wang. A Possibilistic Mean VaR Model for Portfolio Selection. AMO - Advanced Modeling and Optimization, Volume 8, Number 1 (2016).

[4] H.M, Jogiyanto. Teori Portofolio dan Analisis Investasi, Jogjakarta : BPFEYogyakarta, 2017.

[5] Hong-Wei Liu. Linear Programming for Portfolio Selection Based on Fuzzy Decision-Making Theory. The Tenth International Symposium on Operations Research and Its Applications Dunhuang China, August 2011 : 195-202

[6] Kusumadewi, Sri. Aplikasi Logika Fuzzy untuk Pendukung Keputusan. Edisi pertama. PT Graha Ilmu, Yogyakarta. 2014.

[7] Li, J. and $\mathrm{Xu}$, J. A novel portfolio selection model in a hybrid uncertainty environment, The International Journal of Management Science Omega 2017
[8] Masahiro Inuiguchi, Jaroslav Ramik. Possibilistic linear programming: a brief review of fuzzy mathematical programming and a comparison with stochastic programming in portfolio selection problem. Fuzzy Sets and Systems 111 (2010) 3-28.

[9] S.G. Nash \& A. Sofer.Linear and Nonlinear Programming.McGraw-Hill : New York. 2016.

[10] Tim Bursa Efek Indonesia. Sejarah Bursa Efek Indonesia. Didapat dari http://www.idx.co.id/id-

id/beranda/tentangbei/sejarah.aspx; Internet, diakses pada tanggal 19 Juli 2018.

[11] Vercher, E., Bermudez,J.D. and Sgura, J. V. Fuzzy portfolio optimization under downside risk measures, Fuzzy sets and Systems, 2017, 158:769-782.

[12] Yoshimoto, A. The mean-variance approach to portfolio optimization subject to transaction costs, Journal of the operational Research Society of Japan, 2006, 39:99-117. 